\title{
Surgical Treatment of Gastric Gastrointestinal Stromal Tumor
}

\author{
Seong-Ho Kong, and Han-Kwang Yang \\ Department of Surgery, Cancer Research Institute, Seoul National University College of Medicine, Seoul, Korea
}

Gastrointestinal stromal tumor is the most common mesenchymal tumor in the gastrointestinal tract and is most frequently developed in the stomach in the form of submucosal tumor. The incidence of gastric gastrointestinal stromal tumor is estimated to be as high as $25 \%$ of the population when all small and asymptomatic tumors are included. Because gastric gastrointestinal stromal tumor is not completely distinguished from other submucosal tumors, a surgical excisional biopsy is recommended for tumors $>2 \mathrm{~cm}$. The surgical principles of gastrointestinal stromal tumor are composed of an RO resection with a normal mucosa margin, no systemic lymph node dissection, and avoidance of perforation, which results in peritoneal seeding even in cases with otherwise low risk profiles. Laparoscopic surgery has been indicated for gastrointestinal stromal tumors $<5 \mathrm{~cm}$, and the indication for laparoscopic surgery is expanded to larger tumors if the above mentioned surgical principles can be maintained. A simple exogastric resection and various transgastric resection techniques are used for gastrointestinal stromal tumors in favorable locations (the fundus, body, greater curvature side). For a lesion at the gastroesophageal junction in the posterior wall of the stomach, enucleation techniques have been tried preserve the organ's function. Those methods have a theoretical risk of seeding a ruptured tumor, but this risk has not been evaluated by well-designed clinical trials. While some clinical trials are still on-going, neoadjuvant imatinib is suggested when marginally unresectable or multiorgan resection is anticipated to reduce the extent of surgery and the chance of incomplete resection, rupture or bleeding.

Key Words: Gastrointestinal stomal tumors; Surgery; Laparoscopy; Neoadjuvant therapy

\section{Introduction}

Gastrointestinal stromal tumor (GIST) is the most common mesenchymal tumor in the gastrointestinal tract; it originated from the interstitial cells of Cajal or their common stem cell. Although the annual incidence is rare, with approximately 10 cases per million, ${ }^{1}$ asymptomatic GIST is believed to be much more prevalent. ${ }^{2.3}$ The most common location of GISTs is the stomach (55 60\%), although GISTs occur throughout the gastrointestinal tract, including the jejunum and ileum (30\%), duodenum (5\%), and colorectum

Correspondence to: Han-Kwang Yang

Department of Surgery, Cancer Research Institute, Seoul National University College of Medicine, 101 Daehak-ro, Jongno-gu, Seoul 110744 , Korea

Tel: +82-2-2072-3797, Fax: +82-2-3672-0047

E-mail: hkyang@snu.ac.kr

Received March 6, 2013

Revised March 9, 2013

Accepted March 10, 2013
$(5 \%),{ }^{4,5}$ and rarely in the esophagus, appendix, gallbladder, and extragastrointestinal organs such as the mesentery, omentum, and retroperitoneum. ${ }^{6}$ The treatment outcomes have dramatically improved since the introduction of a tyrosine kinase inhibitorimatinib. However, surgery remains the main treatment modality for primary GIST along with multidisciplinary approach, and is also important for metatatic disease with resistant tumor cell clone.

In this artricle, treatment strategies for primary gastric GIST were reviewed, especially focusedfocusing primarily on to the principles of surgerysurgical principles, different surgical approaches depending on the characteristic of GIST, and imatinib treatment before and after surgery.

\section{Diagnosis}

GIST can be detected at any age, but occurs predominantly in adults older than 50 years, with a median age of 55 65 years. 
Kong SH and Yang HK

GISTs occur slightly more frequently in men than women. GIST accounted for $66.8 \%$ of surgically removed gastric submucosal tumors in a national survey in Korea. ${ }^{8}$

The most common symptoms of GIST are abdominal pain or dyspepsia, gastrointestinal bleeding, and an abdominal mass., ${ }^{9} 10$ However, asymptomatic GISTs, especially small lesions less than $1 \mathrm{~cm}$, are frequently found (upto 25\%) in the specimens of total gastrectomy from gastric cancer and autopsies. This means that the c-kit (+) microGIST in the vast majority do not evolve towards overtly malignant behavior., ${ }^{2,3}$

GISTs are often discovered incidentally during computed tomography (CT), endoscopy or gastrography. On endoscopy, typical GISTs present as a bulge in the gastrointestinal tract, with smooth, intact, normal overlying mucosa and cannot be completely differentiated from other mesenchymal tumors, including leiomyomas, leiomyosarcomas, glomus tumors, lipomas, liposarcomas, hemangiomas, neuromas, and granular cell tumors, vascular structures (aneurysms, varices), cysts, pseudocysts, neoplasms of adjacent organs, and even extramural structures. ${ }^{11,12}$ To avoid a misunderstanding that the tumor is originates from the submucosal layer, many gastroenterologists use the term "subepithelial tumor" instead of "submucosal tumor". 13

If the submucosal tumor is suspected to be a GIST and is larger than $2 \sim 3 \mathrm{~cm}$ on endoscopy, surgery is considered to be necessary, and CT and chest X-ray (or chest CT) is needed for metastasis workup. Sometimes the endoscopic finding only reveals a small portion of a large GIST, and a CT scan may reveal the much larger mass.

Endoscopic biopsy usually yields only normal mucosa, but these biopsies can sometimes provide tissue with diagnostic value, especially when an ulcer is present. ${ }^{14}$ Stacked, or biteonbite biopsies, can be attempted, but the diagnostic yield is still poor, in the range of $17 \sim 42 \% .^{15,16}$ Physicians have attempted to obtain tissue after removing the overlying mucosa with electrocautery; however, breaking GIST should be cautiously considered if the surgical plan has the possibility of opening the gastric wall that has a chance of spreading peritoneally from an exposed GIST. ${ }^{17}$

Because of difficulties in pathologic confirmation, other imaging tools can be used to help differentiate between a GIST and other benign diseases presenting as submucosal tumor. Endoscopic ultrasound (EUS) is helpful for distinguishing the GISTs from lipomas or vascular lesions. GISTs are characterized by a hypoechoic appearance and originate from the fourth hypoechoic endosonographic layer on EUS. Irregular extraluminal borders, cystic spaces, echogenic foci, a heterogeneous echotexture and size greater than 30 40 mm, mucosal ulceration, a nonoval shape are all reported to be associated with an increased risk of malignancy. ${ }^{18-20}$ Several criteria have been suggested by combinations of these features. However, these methodologies were derived from retrospective studies and have not been validated in prospective series, and the predictive accuracy of these methodologies have not been well defined. ${ }^{12}$ EUS is recommended if the submucosal tumor is larger than $1 \mathrm{~cm}$ and has the pillow sign, a typical sign associated with lipomas, by the Eckardt's algorithm (in editorial). ${ }^{13}$ Japanese guideline recommended EUS for GIST $>2 \mathrm{~cm}^{21}$ If a GIST does not meet these criteria, it can be followed by annual endoscopic surveillance. Despite good correlations between endoscopic size estimations and EUS measurements, EUS seems to be more accurate, especially for extramural lesions. ${ }^{11}$

EUS guided biopsy is not routinely recommended for lesions that are highly suspicious for GIST, but remains the preferred sampling method by experts. ${ }^{22-24}$ Once adequate sampling is obtained by EUS, the diagnostic accuracy of immunohistochemical analysis can be as good as 80 91\%. ${ }^{25-27}$ However, EUS provides an inadequate tissue yield in up to $33.3 \%$ of the samples. ${ }^{28,29}$ EUS guided core needle biopsy using a 19 gauge Tru-cut needle has been proposed to overcome some of the limitations of endoscopic ultrasound with fine needle aspiration (EUS-FNA). However, because it relies on triggering a springloaded cutting sheath, EUS-FNA use is limited in the fundus, antrum, and duodenal bulb because of the endoscope angulation interfering with its deployment. ${ }^{30}$ Because of the high rate of technical failure of the Tru-cut method, a recent randomized crossover study failed to show the superiority of Trucut biopsy over fine-needle biopsy. ${ }^{31}$

Conventional CT scanning is mainly used for the characterization of large GISTs and for the assessment of metastatic spread and has limitation in the assessment of small GISTs. ${ }^{32,33}$ "Stomach protocol CT", in which the patients ingest tap water or vesicant to distend the stomach with/without 3-dimensional reconstruction, is useful not only for early gastric cancer but also for gastric GIST to localize the mass and to differentiate the mass from other pathologies. ${ }^{34-36}$ Though each disease entity has characteristic features, however, GIST cannot be completely differentiated from other soft tissue tumors due to overlapping CT findings. CT scanning with a distended stomach is helpful for identifying the location and the relationship between the growth type of GIST and the gastric wall. The images can show exophytic or endophytic growth, or if the tumor is growing in both directions in a dumbbell shape. This in- 
formation is helpful for surgeons planning the surgical approach.

Magnetic resonance imaging (MRI) is useful for the patients allergic to contrast media and in cases with questions regarding the liver. ${ }^{37}$ It can be helpful to distinguish GIST from the heterotopic pancreas tissue with atypical gross features by determining if the mass has the same signal as the pancreas. Positron emission tomography (PET)/CT scanning is useful for early treatment response assessment as well as in cases with inconclusive results from CT or MRI. ${ }^{18} \mathrm{~F}$-Fluorodeoxuglucose uptake is correlated with the mitotic index and viable cell activity and is particularly helpful in the assessment of the response of the tumor to the tyrosine kinase inhibitor if the size of the tumor does not decrease, but the active tumor cells are killed by therapy. 37,38

\section{Pathologic Confirmation}

If endoscopy and EUS fail to obtain a biopsy sample, a percutaneous biopsy may be another option for pathologic diagnosis in cases when pathologic confirmation is mandatory. However, a percutaneous biopsy has the possibility to cause tumor seeding. It is reserved for patients with a plan to receive a tyrosine kinase inhibitor as the first line treatment such as those patients with advanced localized disease or metastatic GISTs. Surgical excisional biopsy is generally suggested for the primary resectable GISTs. ${ }^{39,40}$ Recent European Society for Medical Oncology (ESMO) guidelines stated that the risk of percutaneous biopsy is negligible if the procedure is properly performed. $^{41}$

Microscopically, most GISTs demonstrate 3 main histologic subtypes: spindle cell type (most common, 70\%), epithelioid type (20\%), and mixed spindle and epithelioid type (10\%). ${ }^{42}$ Microscopic findings could not differentiate GISTs from other sarcomas untilHirota and collaborators identified the gain-of-function mutations in the KIT gene. Approximately 95\% of GISTs stain positive for the CD117 antigen, an epitope on the KIT receptor tyrosine kinase that is an important protein marker in the diagnosis of GIST. ${ }^{43}$ GISTs that are KIT-negative account for approximately 5\% of cases, and these cases can present diagnostic difficulties. Recently found markers, Discovered on GIST 1 (DOG1) and protein kinase $\mathrm{C}$ (PKC)-theta, are helpful for diagnosing KIT-positive as well as KIT-negative GISTs. ${ }^{44}$ DOG1, or anoctamin 1, is a calciumactivated chloride channel composed of 8 transmembrane domains. The overall sensitivity of DOG1 staining in GIST ranges from 75\% to $100 \%$, and the clone K9 DOG1 antibody was reported to be superior to the DOG1.1 antibody. DOG1 can successfully identify most KIT-positive GISTs and up to one-third of KIT-negative GISTs, the latter mostly harboring PDGFRA mutations. ${ }^{45,46}$ PKCtheta is another marker that is upregulated in in approximately $90 \%$ of GIST cases. It is a member of the serine/threonine family of protein kinases, which are constitutively phosphorylated in GIST, irrespective of KIT immunoreactivity and mutational status. ${ }^{47,48}$ These antibodies can be positive in other immunoreactive tumors. KIT (CD117) can be positive in some melanomas, PEComas, and clear cell sarcomas. DOG-1 can be positive in uterine-type retroperitoneal leiomyomas, peritoneal leiomyomatosis, and synovial sarcomas. PKC-theta can be positive in PNST, smooth muscle tumors, and desmoid tumors. ${ }^{49}$

Approximately $80 \%$ of patients with GIST have the mutated KIT proto-oncogene. ${ }^{50}$ KIT mutations observed in patients with metastatic tumors are most frequently observed in exons $11(67 \%)$, $9(10 \%), 13(1 \%)$, or $17(1 \%),{ }^{51}$ while platelet-derived growth factor receptor $-\alpha$ (PDGFRA) mutations (10\%), which are less common than KIT mutations, occur mostly in exons 18 (6\%), $12(0.7 \%)$, or $14(0.1 \%))^{52}$ Mutational analysis is helpful in detecting the development of secondary mutations in tumors that are responding poorly to tyrosine kinase inhibitors and in identifying the PDGFRA exon 18 codon D842V missense mutation, which is associated with a good prognosis, but conversely confers resistance to imatinib. ${ }^{53,54}$ Exon 9 is reported to benefit from a high dose $(800 \mathrm{mg} /$ day $)$ of imatinib in some studies. ${ }^{55}$ However, exon 9 mutations account for only $1.8 \%$ of gastric GIST, and the usage of high dose imatinib for adjuvant or neoadjuvant treatment requires further study. ${ }^{56}$ GISTs without a mutation in either KIT or PDGFRA (15\%) are referred to as 'wild type', although they may harbor mutations in other genes, including succinate dehydrogenase (SDH) and B-rapidly accelerated fibrosarcoma kinase (BRAF). ${ }^{57,58} \mathrm{SDH}$-deficient GISTs are very rare and are found in pediatric cases and in those associated with the Carney triad or Carney-Stratakis syndromes. ${ }^{59}$

\section{Indication for Surgery}

Every GIST is now considered potentially malignant. If a gastric submucosal tumor cannot be distinguished with high confidence, it is strongly recommended to resect the tumor by most guidelines, especially tumors larger than $2 \mathrm{~cm}$ (Only Eckardt's editorial recommended $3 \mathrm{~cm}$ as an indication for surgery). ${ }^{12,21,23,39,41}$ Smaller tumors may observed because of the low potential for malignancy, though patients should be informed of the possibility of malignancy in spite of the small tumor size. NCCN guidelines suggest surgical 
removal of small GISTs less than $2 \mathrm{~cm}$ if they are accompanied with high risk EUS features such as an irregular border, cystic spaces, ulceration, echogenic foci, or heterogeneity. ${ }^{24}$ However, as previously mentioned, there is no consensus about the criteria to perform EUS for GIST $<2 \mathrm{~cm}$ on endoscopy.

Watchful follow up for small GIST is supported by the observation of Lim et al., ${ }^{60}$ reporting increasing size in only 8 out of 252 (3.2\%) gastric submucosal tumors after a mean interval of $59.1 \pm$ 27.5 months (range, 12 86 months). Only 3 patients underwent surgical operations. Gill et al. ${ }^{61}$ reported increasing size in 7 out of $51(13.7 \%)$ submucosal tumors that were $<3 \mathrm{~cm}$ during mean period of 29.7 months (range, 3 84 months), and three of those patients underwent surgery.

Submucosal tumors near the gastroesophageal junction (GE junction) or the pylorus are sometimes difficult to remove by simple wedge resection and may need distal gastrectomy or proximal gastrectomy, which can cause postgastrectomy functional sequelae. Therefore, more cautious decisions in the multidisciplinary discussion and multiple diagnostic tools such as EUS-guided biopsy, CT, MRI, or PET may be considered.

When the tumor is very large and rupture, bleeding, or extensive combined resection is anticipated, neoadjuvant treatment with imatinib can be considered. The decision of the surgeon is important for deciding the neoadjuvant treatment with the National Comprehensive Cancer Network (NCCN) and ESMO guidelines. ${ }^{24,41}$ When neoadjuvant imatinib is selected, pathologic confirmation is essential by endoscopy, EUS, or percutaneous access. Percutaneous access is typically the last option due to an unproven possibility of peritoneal dissemination of the tumor. Whenever possible, mutational analysis is suggested for identifying a baseline mutation and the presence of PDGFRA D842V mutation, which is known to be resistant to imatinib. Details of neoadjuvant imatinib treatment will be discussed later in this review.

\section{Surgery for Gastric GISTs}

The principles of surgical treatment for primary resectable GIST are complete resection without causing tumor rupture and to acquire negative margins. ${ }^{7,39,40}$ Because GISTs are not infiltrating to the gastric wall like adenocarcinoma, a wide normal mucosal margin is not needed. Although acquirement of gross negative margins is suggested and some recommend $1 \mathrm{~cm}$ margins for convenience and safety, ${ }^{50}$ microscopic negative margins are sufficient to ensure $\mathrm{R} 0$ resection. ${ }^{24}$ Because the frequency of lymph node involvement is low, systemic lymphadenectomy is not generally required. Instead, the removal of enlarged lymph nodes near the tumor, if notified, isusually warranted.

It is written in the NCCN guidelines "Given the limited intramural extension, extended anatomic resections (such as total gastrectomy) are rarely indicated. Segmental or wedge resection to obtain negative margins is often appropriate" ${ }^{24}$ but partial or total gastrectomy is not infrequently needed depending on the size, location, and configuration of the tumor. ${ }^{49}$ In the case of inadvertent tumor infiltration into the surrounding organs, a complete en bloc resection with combined resection of the liver, spleen, pancreas, or colon should be considered. The attachment of GISTs to an adjacent organ is often found to be not a true infiltration, but attempts for isolation of the tumor may cause tumor rupture or a R1 resection.

It is extremely important to avoid tumor rupture because it is associated very poor outcomes, even in small GISTs with low mitotic counts. ${ }^{62,63}$ The tumor should not be held with forceps and should be handled gently. If there is any possibility of tumor rupture, an en bloc combined with a resection or even abandoning surgery and converting to neoadjuvant treatment should be considered. ${ }^{40,41}$

Theoretically, enucleation or shellout procedures are very dangerous because they can result in peritoneal dissemination when the disruption of the pseudocapsule and the perforation of the gastric wall happen simultaneously, even with small tumors. In spite of favorable outcomes from retrospective reports, enucleation procedures, either by an endoscopic or laparoscopic (transgastric) approach, should not be considered a standard treatment when GIST is suspected. ${ }^{39,49}$

Rarely, the tumor suspected to be a GIST is determined to be an adenocarcinoma or a lymphoma. When the pathologic diagnosis is not made at the time of resection, intra-operative or post-operative frozen tissue examination must be performed. In cases of adenocarcinoma, more extensive gastrectomy with systemic lymphadenectomy should be performed as soon as possible. Sometimes, poorly differentiated adenocarcinoma is difficult to distinguish from epithelioid type GIST, so post-operative immunohistochemistry results should be checked rapidly. ${ }^{49}$

\section{Indication for Laparoscopic Surgery}

Because of concerns about tumor rupture from the use forceful laparoscopic forceps, a consensus meeting in 2004 by ESMO recommended laparoscopic resection only for GISTs $\leq 2 \mathrm{~cm}$. How- 
ever, GISTs can be handled without directly holding the mass with forceps, and they can be treated with techniques to prevent rupture and spillage, such as holding surrounding soft tissues or fibrous tissues, suturing at the nearby gastric wall for traction, the usage of endoscopic staplers, plastic bag, and other techniques. ${ }^{64}$ Otani et al. ${ }^{65}$ suggested $5 \mathrm{~cm}$ as an indication for laparoscopic wedge resection, and successful results have been reported with this technique. ${ }^{66}$

Some series reported superiority of laparoscopic wedge resection for GIST over open surgery by showing fast oral intake, less pain, less inflammatory lab results, less blood loss, or shorter hospital stay lengths. ${ }^{67-69}$ Long-term results in terms of recurrence and survival rateswere also comparable to open surgery. ${ }^{70-72}$

The size of the tumor cannot be the sole indicator for laparoscopic procedure because laparoscopic partial or even total gastrectomy can be performed with minimal manipulation of the tumor. Moreover, if the umbilicus is incised and extended approximately $4 \sim 5 \mathrm{~cm}$, a tumor as large as $10 \mathrm{~cm}$ can be put in the plastic bag and extracted without breakage. ${ }^{68,73-75}$ In contrast, open surgery may be recommended even if tumors are smaller than $5 \mathrm{~cm}$, if they have abundant blood flow and high vascularity, if they are fragile. If the tumor is near the GE junction, open surgery can sometimes be safer depending on the location, even for experienced laparoscopic surgeons. Current guidelines and consensus favor recommendations to keep tight principles of surgical resection without limiting the indications for laparoscopic surgery by size. ${ }^{24,41,49}$ However, five centimeters seems to be remaining a practical reference.

Reduced port surgeries, including single incision laparoscopic surgery, can be used, particularly for small GISTs at favorable locations (i.e., the anterior wall, the greater curvature of the body). ${ }^{76-78}$ A 2 mm-sized mini-loop was reported to be useful for holding up the nearby gastric wall. ${ }^{79}$ Robotic surgery using the daVinci system was also reported and is suggested to be useful for the tumors near GE junction. ${ }^{80,81}$ The superiority of these procedures is not definitive compared with the conventional laparoscopic approach. As with cholecystectomy and appendectomy, it is questionable whether reduced port surgery increases patient satisfaction. In robotic surgery, if staplers are used, one surgeon who is operating the daVinci arms and the other surgeon who is applying the stapler should coordinate well with each other. The $8 \mathrm{~mm}$ trocar for the daVinci arm should be installed inside a $12 \mathrm{~mm}$ port if the same site is used for both the stapler and the daVinci arm. Most importantly, it is difficult to justify the high expensive for general usage of the daVinci system for gastric GISTs.

\section{Laparoscopic Surgical Technique Based on Tumor Location}

The location of trocars varies depends on the location of the tumors and operators and is not much different from the locations used in laparoscopic surgeries for early gastric cancer or Nissen fundoplication. The operator can stand either between the legs of the patient or at the right side of the patient, according to the preferences. The location of the trocar for the linear stapler and the needle holder should be selected in consideration with the direction of stapling or suturing. To make a stapler line perpendicular to the long axis of the stomach for the purpose of avoiding stenosis, staplers may be introduced from the left side and the usage of roculating staplers could provide additive help. The location of the trocars is adjusted to the left and proximally for a lesion at the upper stomach, and distally when a lesion is located in the lower stomach. One or two assistants' trocar and an epigastric trocar for liver retraction can be added according to the need. Intra-operative endoscopy or laparoscopic ultrasound may be used to locate small lesions or to assist in resection during the laparoscopic procedure.

Different laparoscopic surgical techniques are used depending on the size and location of the lesions; whether the lesion is located in fundus/body, the antrum or near the GE junction, or antrum; and whether it is on the anterior or the posterior side of the stomach. $^{82,83}$

For anterior wall lesions, the mass is elevated by grabbing nearby normal mucosa or adjacent soft tissue. Seromuscular sutures around the lesion can also be helpful. For the lesions near the lesser curvature or the greater curvature, ligation of the vascular pedicles are facilitated by using laparoscopic energy-based devices. The linear stapler is then applied to resect the mass with nearby normal tissues; this has been called the "exogastric method". If the lesion is growing endophytically, a relatively large amount of normal mucosa is removed by this simple linear stapling method. To prevent stenosis after resection by the removal of excessive normal tissue, the direction of the stapler should be perpendicular to the long axis of the stomach, and multiple staplers may be needed. When stenosis is anticipated even with this method, for example, with a $5 \mathrm{~cm}$ tumor in the anterior wall of the antrum, the so-called "eversion technique" can be applied. ${ }^{84,85}$ A gastrotomy is made either proximally or distally with a gross negative margin of normal mucosa about half the length of the circumference of the tumor. The mass is then everted outside of the stomach, and the gastrotomy and the normal mucosa attached to the mass is stapled in the direction 
perpendicular to the long axis of the stomach. In this maneuver, cautious suction of the intragastric contents should be performed to minimize contamination.

For a lesion at the posterior wall of the stomach, it is often necessary not only to open the gastrohepatic ligament and rotate the stomach caudally but also to open the gastrocolic ligament and rotate the stomach cephalad even for a lesion close to the lesser curvature. The lesion then can be resected with an "exogastric" technique similar to that described for anterior lesions. ${ }^{84}$

If a lesion shows endophytic growth and stenosis is anticipated after the exogastric method, it can be treated using a "transgastric" or "intragastric" approach. The terms "intragastric", "transgastric", or "endoluminal" have been used separately to classify the operative techniques in some articles, but generally have been used without clear definitions and to describe overlapping concepts. The simplest intragastric technique is to make a gastrotomy at the anterior wall of the stomach and elevate the mass, followed by a full thickness resection with a linear stapler through the gastrotomy. ${ }^{86,87}$

When the tumor is located near the pylorus and exogastric or eversion technique is not feasible, distal gastrectomy can be performed. ${ }^{83}$ If stenosis is found after intraoperative stapling or suturing, additive gastrojejunostomy and vagotomy could be a salvage procedure.

GISTs near the GE junction, however, is challenging compared with those in the pylorus because, when stenosis occurs, there is no procedure such as gastrojejunostomy and the stenotic anastomosis must be opened and re-constructed. A proximal gastrectomy can cause severe gastroesophageal reflux. If the surgeon is not convinced about the need for a laparoscopic procedure in difficult cases near the GE junction, the open method should be considered. ${ }^{88}$ For GISTs near the GE junction, endoscopy is helpful for identifying the location of the tumor, for using as a bogie to maintain the passage of the lumen during resection with linear staplers, and for observing bleeding or stenosis after surgery. ${ }^{89}$ Therapeutic endoscopic techniques have also been used for endoluminal resection, too. When endoscopy is used, gas distention in the small bowel can be prevented by clamping the jejunum with a detachable clamp. ${ }^{90}$

When the tumor is located on the anterior side near the GE junction, a simple exogastric resection is possible for some small, exophyting GISTs. However, frequently cutting half of the margin or the whole margin around the mass is needed to minimize the loss of normal tissue. After cutting the gastric wall using either energy-based devices or electrocautery, the defect in the gastric wall is approximated together with the stay sutures and hanged up, or a defect and normal mucosa attached to the tumor are lifted up together in an eversion technique. Finally, a linear stapler completes the resection while the endoscopy is kept in the GE junction to prevent stenosis. ${ }^{84,91,92}$

For tumors located at the posterior wall near the GE junction, several intragastric resection methods have been suggested. Similar to the method previously described, linear stapler can be introduced via gastrotomy at the anterior wall of the stomach and resection can be made inside the stomach. ${ }^{93,94}$ Instead of using a gastrotomy, laparoscopic trocars can be penetrated into the gastric wall and laparoscopic forceps and a linear stapler can be inserted in the socalled "transgastric" route. Either an endoscopic view or a laparoscopic camera, which is inserted into the stomach via a transgastric trocar, can be used for visualizing the surgical view. To prevent retraction of the trocars, balloon trocars were preferably used. .3,95-97 $^{\text {. }}$

Some groups reported the enucleation technique mainly using endoscopic submucosal dissection (ESD) techniques and aided by laparoscopic forceps inserted through transgastric trocars, or using laparoscopic electrocautery or energy-based devices. ${ }^{98-102}$ The specimen is usually removed by endoscopy. When a perforation developed, laparoscopic sutures were performed either inside the stomach or outside the stomach after relocating the transgastric trocars into the abdominal cavity. The trocar insertion site was also sutured laparoscopically in the same manner.

Though successful results were reported with these intragastric or transgastric techniques, these methods do not resect the full thickness of the stomach and can be applied only to endophytically growing GISTs. Unlike the stapling the entire layer through the anterior wall gastrotomy for the GISTs located at the posterior wall of the stomach body, full thickness stapling is not easy except in very small lesions near the GE junction. ${ }^{103,104}$ In this sense, although these techniques could obtain better surgical margins by effective transition using laparoscopic forceps and could securely close the defect when the perforation occurs, compared with purely endoscopic enucleation techniques, the risk of incomplete resection and peritoneal dissemination when accompanied with simultaneous gastric wall perforation should be considered. The patients must be informed of the risk before the operation.

In contrast, by a method reported by Hiki's group described as "laparoscopic endoscopic cooperative surgery (LECS)", a fullthickness resection is performed by sequential endoscopic and laparoscopic dissection. At first, both the mucosal and submucosal layers around the tumor were circumferentially dissected using ESD via intraluminal endoscopy. Subsequently, the seromuscularlayer 
was laparoscopically dissected on the exact three-fourths cut line around the tumor. The submucosal tumor was then exteriorized to the abdominal cavity and dissected with a standard endoscopic stapling device. ${ }^{105}$ Abe et al. ${ }^{106}$ also reported a similar technique named "laparoscopy-assisted endoscopic full-thickness resection (LAEFR)". The differences are that the full thickness resection is performed by an endoscopic method and that the gastric wall defect is closed by handsewn techniques. In both techniques, the precise resection margin with small normal mucosa was suggested as an advantage of endoscopic dissection and was safely reproduced in a series of 20 patients by Tsujimoto et al. ${ }^{107}$

The hepatic or celiac branch of the vagus nerve can be usually spared in the removal of GISTs near the GE junction. Even when the vagus nerve is injured, routine pyloroplasty may not be needed, and the use of this procedure is debatable after proximal gastrectomy or Ivor-Lewis operations. ${ }^{108}$

Lee et al. ${ }^{109}$ suggested anterior partial fundoplication (Dor) in cases when the lower esophageal sphincter seemed to be destructed, as in the operation for achalasia. The effectiveness of this prophylactic anti-reflux procedure requires further evaluation.

\section{Endoscopic Enucleation}

Although many experts and guidelines suggested complete R0 resection with negative margins of normal mucosa for GISTs, a large number of reports were published about endoscopic enucleation techniques for gastric submucosal tumors. Endoscopic treatments typically targeted small GISTs to eliminate a need for lifelong surveillance and the fear of the patients regarding the small but real possibility of malignant transformations. The modalities of endoscopic treatment include band ligation and/or additive resection, polypectomy snare, and the most frequently used submucosal dissection methods.

The enucleation method for GIST has higher risk of perforation than those methods used in early gastric cancer because GIST originates from a proper muscle layer and deeper dissection is necessary for the complete dissection. ${ }^{110,111}$ Additionally, a risk of incomplete resection coexists because GISTs are frequently fragile and do not form a true capsule. For example, the incomplete resection rate was 3/65 (4.6\%) in Jeong's report, ${ }^{112} 3 / 12$ (25\%) in Lee' s report, ${ }^{113} 7 / 22$ (31.8\%) in Białek's report, ${ }^{114}$ and 8/143 (5.6\%) in Li's report, ${ }^{115}$ and the perforation rate was 8/65 (12.3\%) in Jeong' s report, ${ }^{112} 7 / 25$ (28\%) in Bai's report, ${ }^{116} 3 / 20$ (15\%) in Catalano' s report, ${ }^{117} 5 / 30(16.7 \%)$ in Białek's report, ${ }^{114}$ respectively. The GE junction area, which is challenging for surgical treatment, is also a difficult and risky location for endoscopic resection because of the narrow lumen and sharp angle. ${ }^{118}$

Although all these reports did not find recurrant GIST among cases with incomplete resection or perforation of the gastric wall, safety cannot be ensured because these reports were not based on clinical trials but based on retrospective reviews. Therefore, it is not clear whether every patient was followed up with or whether CT scans were performed to identify the presence of peritoneal recurrence.

Waterman et al. ${ }^{119}$ reported a case of a $1.6 \times 1.8-\mathrm{cm} \mathrm{c}^{-}$kitpositive GIST with low mitotic activity in the gastric fundus. The patient underwent an attempted endoscopic resection of this mass resulting in incomplete excision and gastric perforation. Three years later, the patient was noted to have an asymptomatic large pelvic mass $(4 \times 7 \mathrm{~cm})$ on a $\mathrm{CT}$ scan, which was preceded by a previous endoscopic procedure.

Nishimura et al. ${ }^{67}$ also reported a higher recurrence rate of the enucleation method in surgery; $1 / 3$ recurrence in three laparoscopic enucleations and 2/6 recurrent in six open enucleations. An endoscopic full thickness resection method also has been attempted without laparoscopic assistance. However, a high failure rate of secure closure of the gastric wall defect by titanium clips and a possible risk of bleeding from perigastric vessels should be overcome by new techniques, but presently, a laparoscopic-assisted procedure seems to be safer. ${ }^{120,121}$

\section{Estimation of Prognosis Estimation and Adjuvant Imatinib}

One of main purposes of estimating the risk of relapse after an operation is to decide to use imatinib as an adjuvant. Fletcher et al. $^{42}$ (National Institutes of Health [NIH] consensus criteria) proposed a risk assessment model with two factors: 1) size and 2) mitotic count. Later, Miettinen and Lasota ${ }^{6}$ (Armed Forces Institute of Pathology [AFIP] criteria) added 3) tumor site; stomach GIST has better prognosis than small bowel and other sites. Gold et al. ${ }^{122}$ made a nomogram to estimate 2-year and 5-year relapsefree survival rate for each patient with these 3 factors. UICC/AJCC TNM classification separately classified stages for gastric GISTs and small bowel GISTs. This classificaitondefined $\mathrm{T}$ staging with the size of the tumor $(2,5$ and $10 \mathrm{~cm})$ and incorporated the mitotic rate for staging grouping. This grouped any N1 or M1 as stage IV, but the presence of N1 is usually not regarded as an important factor 
because of the rare incidence and not well proven significance. ${ }^{123}$ Joensuu et al. ${ }^{6}$ showed that 4 ) tumor rupture as well as the previous 3 factors is an important risk factor associated with a very poor prognosis.

The effect of adjuvant imatinib was proven in the American College of Surgeons Oncology Group (ACOSOG) Z9001 study of patients with tumor diameter $\geq 3 \mathrm{~cm}$ who received imatinib for one year following complete surgical resection, and this study showed a significant improvement in recurrence-free survival with imatinib therapy. The benefit was markedly observed in patients with tu ${ }^{-}$ mors $\geq 10 \mathrm{~cm}$. This study did not show an improvement in overall survival, and the recurrence rate increased sharply for patients after imatinib interruption, suggesting that prolonged use of adjuvant imatinib beyond 1 year may be required for further reduction in the risk of recurrence. ${ }^{124}$ The recently completed randomized controlled SSGXVIII/AIO trial suggested that adjuvant imatinib administered for 36 months improved not only the recurrence-free survival but also overall survival, compared to adjuvant imatinib that was administered for 12 months, for patients with a high estimated risk of recurrence after surgery. ${ }^{125}$

With the currently available data, it is recommended to use 3 years of imatinib for patients with a high relapse risk, and imatinib is not indicated for those at low relapse risk. However, there is no consensus for patients with an intermediate risk. A nonrandomized, open-label, multicenter, phase II PERSIST 5 study is evaluating 5 years of adjuvant imatinib in patients at a significant risk of recurrence following complete resection of primary GIST (CST1571BUS282, ClinicalTrials.gov identifier: NCT00867113).

Imatinib has been found to be effective not only for GIST with C-KIT mutations but also for GIST with PDGFRA mutations and for wild-type GISTs. ${ }^{51,126}$ However, no adjuvant treatment is recommended in GISTs with the D842V missense mutation in the PDGFRA exon 18, which are known to be unresponsive to imatinib and showed very favorable outcome after surgery. ${ }^{41}$ GIST with KIT exon 9 mutations were found to have a very poor prognosis, but they have not been found to have a significant reduction of the risk of relapse from 1 year nor 3 year adjuvant treatment. Some investigators advocate for the use of $800 \mathrm{mg}$ per day of adjuvant imatinib in this setting, but no study has been performed using this dose in this situation. ${ }^{50}$

If the operation was found to be R1 with positive margins, the ESMO guideline recommends re-excision if the original site of the lesion can be found and major functional sequelae are not foreseen. R1 surgery alone has been not proven to be high-risk feature; hence, there has been no consensus whether to initiate adjuvant imatinib in otherwise low-risk patients who underwent R1 resection or whether R1 resection is regarded as ruptured, which might have high risk of peritoneal seeding. ${ }^{127-129}$

If the tumor ruptures, one may consider lifelong imatinib treatment in the metastatic disease setting because tumor rupture may carry a similar risk of progression to metastatic disease. A high recurrence rate was reported in ruptured GISTs with otherwise low risk features. ${ }^{62,130}$ The presence of rupture should be well documented in the operating records, and if the surgical report is unclear, surgical and medical oncologists should stay in good communication to accurately establish the patient's risk of recurrence. ${ }^{127}$

\section{Post-Operative Follow-Up and Surveillance}

High-risk patients generally relapse within 1 2 years after discontinuing adjuvant therapy. The optimal follow-up schedules are not known. For example, high- and intermediate-risk patients may need routine follow-up with CT scanning or MRI every 3 6 months during adjuvant imatinib therapy and then after cessation of adjuvant therapy, every 3 months for 2 years, and then every 6 months until 5 years after stopping adjuvant therapy and then annually. ${ }^{7,39-41,49}$ If adjuvant imatinib is not used in intermediate-risk patients, CT or MRI every 3 4 months for 3 years after surgery, every 6 months until 5 years after surgery, and an annual assess ${ }^{-}$ ment thereafter could be used. For low-risk patients, CT or MRI every $6 \sim 12$ months for 5 years may be indicated, though the usefulness of routine follow-up is not known. Very low-risk GIST patients likely do not need a routine follow-up.

\section{Neoadjuvant Imatinib}

In several reports, pre-operative imatinib was found to be an effective and safe treatment for GIST, especially locally advanced or marginally resectable tumors. Goh et al. ${ }^{131}$ reported an 89\% (33/37) of complete resection rate after neoadjuvant treatment. Andtbacka et al. ${ }^{132}$ reported an $82 \%(29 / 35)$ response rate and a 100\% complete resection rate. Hohenberger and Eisenberg ${ }^{133}$ reported 92\% (33/36) patients who completed 6 months ofneoadjuvant treatment and $90 \%$ of them had complete tumor removal. Moreover, five of the six patients that were previously considered inoperable underwent surgery after neoadjuvant treatment. Similarly successful complete resections and more conservative R0 resections than previously expected were reported in the Phase II trial of Doyon et al. ${ }^{134}$ 
Together with the general advantages of neoadjuvant treatment, including the reduced extent of resection of organs, it seems be especially advantageous to reduce the risk of rupture using neoadjuvant imatinib treatment in large GISTs. The indications for a neoadjuvant trial are not defined by specific objective features such as size, but are left to the decision of clinicians in the NCCN and ESMO guidelines. "If the surgeon feels that a multi-visceral resection may be required", or "if the surgeon believes that the surgical conduct is safer after cytoreduction (e.g., the risk of bleeding and tumor rupture is decreased)", neoadjuvant imatinib can be considered. $^{24,41}$

Like neoadjuvant treatment for rectal saving, GISTs near the GE junction or the pylorus might be indicated for neoadjuvant imatinib to save function, although this has not been proven. The condition is that histopathologic diagnosis should be made by endoscopic or EUS-guided biopsy. If diagnosis fails, the GIST has to be large (i.e., $\geq 10 \mathrm{~cm}$ ) enough to justify potentially dangerous percutaneous biopsy for neoadjuvant treatment.

Daily $400 \mathrm{mg}$ administration of imatinib is now generally being considered to be adequate for neoadjuvant treatment, based on previous studies of metastatic GISTs. There is no evidence to support higher dosage for GISTs with exon 9 in a neoadjuvant setting. The duration of neoadjuvant imatinib should be longer than 4 6 months and within 12 months because the maximal response is generally obtained during this period and no further response is expected after 12 months. ${ }^{133,135}$ Imatinib is recommended to be continued until a few days before surgery and to be re-initiated postoperatively as soon as diet is resumed. There is no consensus about the duration of postoperative imatinib, but at least 3 years either postoperatively only or combining pre- and postoperative periods should be considered, based on the recent result of an adjuvant imatinib treatment study that showed better survival with 3 years of treatment than with 1 year of treatment. ${ }^{125}$

Although the disease is well controlled with imatinib, surgery should be performed after neoadjuvant treatment because complete response is rare with imatinib and secondary mutations and resistant clones frequently develop after 2 years of imatinib treatment. ${ }^{53,136}$ Additionally, the group that underwent an operation after neoadjuvant treatment showed better progression-free survival than the non-operation group in a subanalysis of BFR14 trial, a phase III study comparing interruption vs. continuation of imatinib, only for patients with locally advanced non-metastatic GIST. ${ }^{137}$

The most concerning issue of neoadjuvant therapy is progression without response to imatinib. Non-responsiveness is expected to be less than $10 \%$ considering the $12 \%$ progression rate of GIST in the subanalysis of the BFR14 trial. Close follow-up and assessment of the therapeutic effect should be performed, and a CT scan every 3 months is generally recommended. ${ }^{138}$ Choi's criteria, which assesses the response by housefield unit, or PET scanning can be helpful when the size of the tumor does not change but the inside of the tumor undergoes necrosis because of imatinib. ${ }^{1.39}$ To detect rapid progression, the ESMO guidelines recommend PET scanning or PET CT/MRI within a few weeks to keep surgical opportunities. $^{41,140}$

To initiate neoadjuvant imatinib, pathologic confirmation is essential as described before. Mutational analysis is also recommended as long as possible to avoid ineffective treatment with imatinib to GIST with PDGFRA D842v mutation.

Infrequently, perforation can occur because of the rapid necrosis of the tumor. We have experienced a $13 \times 7.6 \mathrm{~cm}$ sized GIST with an ulcer inside the stomach of 51-year-old female, who developed fever 3 days after the initiation of imatinib, due to the rapid necrosis of the tumor. She had a perforation 13 days later. It was also suspicious that the ulcer area acted as a check valve, allowing air from the stomach to enter into the mass and remain trapped. Our policy after that is to admit patients with huge GISTs, especially with ulceration, for several days after the initiation of imatinib for close observation.

Two multicenter phase II trials are currently ongoing. A trial in Korea and Japan (CSTI571BJP09T) is indicated for gastric GISTs $\geq 10 \mathrm{~cm}$. The target is 40 patients and the primary outcome is progression-free survival. In this trial, $400 \mathrm{mg} / \mathrm{d}$ of imatinib is used for $6 \sim 9$ months preoperatively and for 12 months postoperatively. ${ }^{141}$ The Apollon trial (CST1571 BDE43), a German multicenter trial, has completed the enrollment of 40 patients with locally advanced GIST. The primary endpoint is the overall tumor response, and $400 \mathrm{mg}$ of imatinib is used for $4 \sim 6$ months. ${ }^{142}$ Recently, results of the RTOG 0132 phase II trial were reported. Patients with primary GIST ( $\geq 5 \mathrm{~cm}$, group A) or resectable metastatic/recurrent GIST ( $\geq 2 \mathrm{~cm}$, group B) received neoadjuvant imatinib $(600 \mathrm{mg} / \mathrm{d})$ for approximately 2 months and maintenance postoperative imatinib for 2 years. The estimated 5-year progression-free survival and the overall survival were $57 \%$ in group A, 30\% in group B, and $77 \%$ in group A, 68\% in group B, respectively. The long-term analysis suggests a high percentage of patients experienced disease progression after discontinuation of 2-year maintenance imatinib therapy after surgery. Consideration should be given to studying longer treatment durations in intermediate- to high-risk GIST patients. ${ }^{143}$ 


\section{Conclusion}

GIST is not a common disease. The stomach is the most frequent site of GIST, and the incidence of GIST, including the indolent stages is believed to be much higher. Because of the inability to distinguish GIST from other gastric submucosal tumors and the possibility of malignant features, excisional biopsy with minimally invasive surgical techniques has been the best treatment option. Minimally invasive techniques could be applied to gastric GIST even for a relatively large size tumor, if the surgical principles for GISTs are followed to obtain an R0 resection with normal mucosal margins and to avoid perforation. The treatment of GIST near the GE junction is challenging, and the risks of enucleation methods must not be overlooked by the results of retrospective case series. Neoadjuvant imatinib for large GISTs is suggested by most guidelines, and ongoing phase II trials may provide additional evidence and new information.

\section{References}

1. Mucciarini C, Rossi G, Bertolini F, Valli R, Cirilli C, Rashid $\mathrm{I}$, et al. Incidence and clinicopathologic features of gastrointestinal stromal tumors. A population-based study. BMC Cancer 2007;7:230.

2. Kawanowa K, Sakuma Y, Sakurai S, Hishima T, Iwasaki Y, Saito K, et al. High incidence of microscopic gastrointestinal stromal tumors in the stomach. Hum Pathol 2006;37:15271535.

3. Agaimy A, Dirnhofer S, Wünsch PH, Terracciano LM, Tornillo L, Bihl MP. Multiple sporadic gastrointestinal stromal tumors (GISTs) of the proximal stomach are caused by different somatic KIT mutations suggesting a field effect. Am J Surg Pathol 2008;32:1553-1559.

4. Kindblom LG, Remotti HE, Aldenborg F, Meis-Kindblom JM. Gastrointestinal pacemaker cell tumor (GIPACT): gastrointestinal stromal tumors show phenotypic characteristics of the interstitial cells of Cajal. Am J Pathol 1998;152:12591269.

5. Cho MY, Sohn JH, Kim JM, Kim KM, Park YS, Kim WH, et al. Current trends in the epidemiological and pathological characteristics of gastrointestinal stromal tumors in Korea, 2003-2004. J Korean Med Sci 2010;25:853-862.

6. Miettinen M, Lasota J. Gastrointestinal stromal tumors: pathology and prognosis at different sites. Semin Diagn Pathol
2006;23:70-83.

7. DeMatteo RP, Lewis JJ, Leung D, Mudan SS, Woodruff JM, Brennan MF. Two hundred gastrointestinal stromal tumors: recurrence patterns and prognostic factors for survival. Ann Surg 2000;231:51-58.

8. The Information Committee of the Korean Gastric Cancer Association. 2005 2006 nationwide gastric submucosal tumor report in Korea. J Korean Gastric Cancer Assoc 2008;8:104-109.

9. Yang HK, Park do J, Lee HJ, Kim HH, Kim WH, Lee KU. Clinicopathologic characteristics of gastrointestinal stromal tumor of the stomach. Hepatogastroenterology 2008;55:19251930.

10. Cassier PA, Ducimetière F, Lurkin A, Ranchère-Vince D, Scoazec JY, Bringuier PP, et al. A prospective epidemiological study of new incident GISTs during two consecutive years in Rhône Alpes region: incidence and molecular distribution of GIST in a European region. Br J Cancer 2010;103:165-170.

11. Hwang JH, Saunders MD, Rulyak SJ, Shaw S, Nietsch H, Kimmey MB. A prospective study comparing endoscopy and EUS in the evaluation of GI subepithelial masses. Gastrointest Endosc 2005;62:202-208.

12. Sepe PS, Brugge WR. A guide for the diagnosis and management of gastrointestinal stromal cell tumors. Nat Rev Gastroenterol Hepatol 2009;6:363-371.

13. Eckardt AJ, Wassef W. Diagnosis of subepithelial tumors in the GI tract. Endoscopy, EUS, and histology: bronze, silver, and gold standard? Gastrointest Endosc 2005;62:209-212.

14. Nowain A, Bhakta H, Pais S, Kanel G, Verma S. Gastrointestinal stromal tumors: clinical profile, pathogenesis, treatment strategies and prognosis. J Gastroenterol Hepatol 2005;20:818-824.

15. Hunt GC, Smith PP, Faigel DO. Yield of tissue sampling for submucosal lesions evaluated by EUS. Gastrointest Endosc 2003;57:68-72.

16. Cantor MJ, Davila RE, Faigel DO. Yield of tissue sampling for subepithelial lesions evaluated by EUS: a comparison between forceps biopsies and endoscopic submucosal resection. Gastrointest Endosc 2006;64:29-34.

17. Kataoka M, Kawai T, Yagi K, Sugimoto H, Yamamoto K, Hayama Y, et al. Mucosal cutting biopsy technique for histological diagnosis of suspected gastrointestinal stromal tumors of the stomach. Dig Endosc 2012. [Epub ahead of print]

18. Karaca C, Turner BG, Cizginer S, Forcione D, Brugge W. Ac- 
curacy of EUS in the evaluation of small gastric subepithelial lesions. Gastrointest Endosc 2010;71:722-727.

19. Palazzo L, Landi B, Cellier C, Cuillerier E, Roseau G, Barbier JP. Endosonographic features predictive of benign and malignant gastrointestinal stromal cell tumours. Gut 2000;46:8892.

20. Jeon SW, Park YD, Chung YJ, Cho CM, Tak WY, Kweon YO, et al. Gastrointestinal stromal tumors of the stomach: endosonographic differentiation in relation to histological risk. J Gastroenterol Hepatol 2007;22:2069-2075.

21. Nishida T, Hirota S, Yanagisawa A, Sugino Y, Minami M, Yamamura Y, et al; GIST Guideline Subcommittee. Clinical practice guidelines for gastrointestinal stromal tumor (GIST) in Japan: English version. Int J Clin Oncol 2008;13:416-430.

22. Blackstein ME, Blay JY, Corless C, Driman DK, Riddell R, Soulières D, et al; Canadian Advisory Committee on GIST. Gastrointestinal stromal tumours: consensus statement on diagnosis and treatment. Can J Gastroenterol 2006;20:157163.

23. Hwang JH, Rulyak SD, Kimmey MB; American Gastroenterological Association Institute. American Gastroenterological Association Institute technical review on the management of gastric subepithelial masses. Gastroenterology 2006;130:2217-2228.

24. NCCN guideline for soft tissue sarcoma; 2012 [cited 2013 Feb 1]. Available from: http://www.nccn.org/professionals/ physician_gls/f_guidelines.asp\#sarcoma.

25. Ando N, Goto H, Niwa Y, Hirooka Y, Ohmiya N, Nagasaka T, et al. The diagnosis of GI stromal tumors with EUS-guided fine needle aspiration with immunohistochemical analysis. Gastrointest Endosc 2002;55:37-43.

26. Vander Noot MR 3rd, Eloubeidi MA, Chen VK, Eltoum I, Jhala $\mathrm{D}$, Jhala $\mathrm{N}$, et al. Diagnosis of gastrointestinal tract lesions by endoscopic ultrasound-guided fine-needle aspiration biopsy. Cancer 2004;102:157-163.

27. Fu K, Eloubeidi MA, Jhala NC, Jhala D, Chhieng DC, Eltoum IE. Diagnosis of gastrointestinal stromal tumor by endoscopic ultrasound-guided fine needle aspiration biopsy--a potential pitfall. Ann Diagn Pathol 2002;6:294-301.

28. Rodriguez SA, Faigel DO. Endoscopic diagnosis of gastrointestinal stromal cell tumors. Curr Opin Gastroenterol 2007;23:539-543.

29. Wiersema MJ, Wiersema LM, Khusro Q, Cramer HM, Tao LC. Combined endosonography and fine-needle aspiration cytology in the evaluation of gastrointestinal lesions. Gastrointest Endosc 1994;40:199-206.

30. Levy MJ, Wiersema MJ. EUS-guided Trucut biopsy. Gastrointest Endosc 2005;62:417-426.

31. Fernández-Esparrach G, Sendino O, Solé M, Pellisé M, Colomo L, Pardo A, et al. Endoscopic ultrasound-guided fineneedle aspiration and trucut biopsy in the diagnosis of gastric stromal tumors: a randomized crossover study. Endoscopy 2010;42:292-299.

32. Ghanem N, Altehoefer C, Furtwängler A, Winterer J, Schäfer $\mathrm{O}$, Springer $\mathrm{O}$, et al. Computed tomography in gastrointestinal stromal tumors. Eur Radiol 2003;13:1669-1678.

33. Goto O, Kambe H, Niimi K, Mochizuki S, Asada-Hirayama I, Minatsuki C, et al. Discrepancy in diagnosis of gastric submucosal tumor among esophagogastroduodenoscopy, CT, and endoscopic ultrasonography: a retrospective analysis of 93 consecutive cases. Abdom Imaging 2012;37:1074-1078.

34. Horton KM, Juluru K, Montogomery E, Fishman EK. Computed tomography imaging of gastrointestinal stromal tumors with pathology correlation. J Comput Assist Tomogr 2004;28:811-817.

35. Choi JW, Choi D, Kim KM, Sohn TS, Lee JH, Kim HJ, et al. Small submucosal tumors of the stomach: differentiation of gastric schwannoma from gastrointestinal stromal tumor with CT. Korean J Radiol 2012;13:425-433.

36. Ulusan S, Koc Z, Kayaselcuk F. Gastrointestinal stromal tumours: CT findings. Br J Radiol 2008;81:618-623.

37. Kalkmann J, Zeile M, Antoch G, Berger F, Diederich S, Dinter D, et al; German GIST Imaging Working Group. Consensus report on the radiological management of patients with gastrointestinal stromal tumours (GIST): recommendations of the German GIST Imaging Working Group. Cancer Imaging 2012;12:126-135.

38. Kamiyama Y, Aihara R, Nakabayashi T, Mochiki E, Asao T, Kuwano H, et al. 18F-fluorodeoxyglucose positron emission tomography: useful technique for predicting malignant potential of gastrointestinal stromal tumors. World J Surg 2005;29:1429-1435.

39. Blay JY, Bonvalot S, Casali P, Choi H, Debiec-Richter M, Dei Tos AP, et al; GIST Consensus Meeting Panelists. Consensus meeting for the management of gastrointestinal stromal tumors. Report of the GIST Consensus Conference of 20 21 March 2004, under the auspices of ESMO. Ann Oncol 2005; 16:566-578. 
40. Gold JS, Dematteo RP. Combined surgical and molecular therapy: the gastrointestinal stromal tumor model. Ann Surg 2006;244:176-184.

41. ESMO / European Sarcoma Network Working Group. Gastrointestinal stromal tumors: ESMO Clinical Practice Guidelines for diagnosis, treatment and follow-up. Ann Oncol 2012;23 Suppl 7:vii49-55.

42. Fletcher CD, Berman JJ, Corless C, Gorstein F, Lasota J, Longley BJ, et al. Diagnosis of gastrointestinal stromal tumors: A consensus approach. Hum Pathol 2002;33:459-465.

43. Hirota S, Isozaki K, Moriyama Y, Hashimoto K, Nishida T, Ishiguro S, et al. Gain-of-function mutations of c-kit in human gastrointestinal stromal tumors. Science 1998;279:577580.

44. Kang GH, Srivastava A, Kim YE, Park HJ, Park CK, Sohn TS, et al. DOG1 and PKC- $\theta$ are useful in the diagnosis of KIT-negative gastrointestinal stromal tumors. Mod Pathol 2011;24:866-875.

45. Liegl B, Hornick JL, Corless CL, Fletcher CD. Monoclonal antibody DOG1.1 shows higher sensitivity than KIT in the diagnosis of gastrointestinal stromal tumors, including unusual subtypes. Am J Surg Pathol 2009;33:437-446.

46. Lopes LF, West RB, Bacchi LM, van de Rijn M, Bacchi CE. DOG1 for the diagnosis of gastrointestinal stromal tumor (GIST): comparison between 2 different antibodies. Appl Immunohistochem Mol Morphol 2010;18:333-337.

47. Kim KM, Kang DW, Moon WS, Park JB, Park CK, Sohn JH, et al. PKCtheta expression in gastrointestinal stromal tumor. Mod Pathol 2006;19:1480-1486.

48. Duensing A, Joseph NE, Medeiros F, Smith F, Hornick JL, Heinrich MC, et al. Protein Kinase C theta (PKCtheta) expression and constitutive activation in gastrointestinal stromal tumors (GISTs). Cancer Res 2004;64:5127-5131.

49. Kang YK, Kang HJ, Kim KM, Sohn T, Choi D, Ryu MH, et al; Korean GIST Study Group (KGSG). Clinical practice guideline for accurate diagnosis and effective treatment of gastrointestinal stromal tumor in Korea. Cancer Res Treat 2012;44:85-96.

50. Blay JY, Le Cesne A, Cassier PA, Ray-Coquard IL. Gastrointestinal stromal tumors (GIST): a rare entity, a tumor model for personalized therapy, and yet ten different molecular subtypes. Discov Med 2012;13:357-367.

51. Heinrich MC, Corless CL, Demetri GD, Blanke CD, von Mehren M, Joensuu $\mathrm{H}$, et al. Kinase mutations and imatinib response in patients with metastatic gastrointestinal stromal tumor. J Clin Oncol 2003;21:4342-4349.

52. Heinrich MC, Corless CL, Duensing A, McGreevey L, Chen CJ, Joseph N, et al. PDGFRA activating mutations in gastrointestinal stromal tumors. Science 2003;299:708-710.

53. Heinrich MC, Maki RG, Corless CL, Antonescu CR, Harlow A, Griffith D, et al. Primary and secondary kinase genotypes correlate with the biological and clinical activity of sunitinib in imatinib-resistant gastrointestinal stromal tumor. J Clin Oncol 2008;26:5352-5359.

54. Corless CL, Schroeder A, Griffith D, Town A, McGreevey L, Harrell P, et al. PDGFRA mutations in gastrointestinal stromal tumors: frequency, spectrum and in vitro sensitivity to imatinib. J Clin Oncol 2005;23:5357-5364.

55. Gronchi A, Blay JY, Trent JC. The role of high-dose imatinib in the management of patients with gastrointestinal stromal tumor. Cancer 2010;116:1847-1858.

56. Wardelmann E, Hohenberger P, Reichardt P, MerkelbachBruse S, Schildhaus HU, Büttner R. Gastrointestinal stromal tumors of the stomach. Updates and differences compared to other locations. Pathologe 2010;31:195-198.

57. Pasini B, McWhinney SR, Bei T, Matyakhina L, Stergiopoulos S, Muchow M, et al. Clinical and molecular genetics of patients with the Carney-Stratakis syndrome and germline mutations of the genes coding for the succinate dehydrogenase subunits SDHB, SDHC, and SDHD. Eur J Hum Genet 2008;16:79-88.

58. Agaram NP, Wong GC, Guo T, Maki RG, Singer S, Dematteo RP, et al. Novel V600E BRAF mutations in imatinib-naive and imatinib-resistant gastrointestinal stromal tumors. Genes Chromosomes Cancer 2008;47:853-859.

59. Miettinen M, Wang ZF, Sarlomo-Rikala M, Osuch C, Rutkowski P, Lasota J. Succinate dehydrogenase-deficient GISTs: a clinicopathologic, immunohistochemical, and molecular genetic study of 66 gastric GISTs with predilection to young age. Am J Surg Pathol 2011;35:1712-1721.

60. Lim YJ, Son HJ, Lee JS, Byun YH, Suh HJ, Rhee PL, et al. Clinical course of subepithelial lesions detected on upper gastrointestinal endoscopy. World J Gastroenterol 2010;16:439444.

61. Gill KR, Camellini L, Conigliaro R, Sassatelli R, Azzolini F, Messerotti A, et al. The natural history of upper gastrointestinal subepithelial tumors: a multicenter endoscopic ultrasound survey. J Clin Gastroenterol 2009;43:723-726. 
62. Joensuu H, Vehtari A, Riihimäki J, Nishida T, Steigen SE, Brabec P, et al. Risk of recurrence of gastrointestinal stromal tumour after surgery: an analysis of pooled population-based cohorts. Lancet Oncol 2012;13:265-274.

63. Rutkowski P, Nowecki ZI, Michej W, Debiec-Rychter M, Woźniak A, Limon J, et al. Risk criteria and prognostic factors for predicting recurrences after resection of primary gastrointestinal stromal tumor. Ann Surg Oncol 2007;14:20182027.

64. Yahchouchy-Chouillard E, Etienne JC, Fagniez PL, Adam R, Fingerhut A. A new "no-touch" technique for the laparoscopic treatment of gastric stromal tumors. Surg Endosc 2002;16:962-964.

65. Otani Y, Furukawa T, Yoshida M, Saikawa Y, Wada N, Ueda $\mathrm{M}$, et al. Operative indications for relatively small $(2-5 \mathrm{~cm})$ gastrointestinal stromal tumor of the stomach based on analysis of 60 operated cases. Surgery 2006;139:484-492.

66. Ryu KJ, Jung SR, Choi JS, Jang YJ, Kim JH, Park SS, et al. Laparoscopic resection of small gastric submucosal tumors. Surg Endosc 2011;25:271-277.

67. Nishimura J, Nakajima K, Omori T, Takahashi T, Nishitani A, Ito T, et al. Surgical strategy for gastric gastrointestinal stromal tumors: laparoscopic vs. open resection. Surg Endosc 2007;21:875-878.

68. Karakousis GC, Singer S, Zheng J, Gonen M, Coit D, DeMatteo RP, et al. Laparoscopic versus open gastric resections for primary gastrointestinal stromal tumors (GISTs): a sizematched comparison. Ann Surg Oncol 2011;18:1599-1605.

69. De Vogelaere K, Hoorens A, Haentjens P, Delvaux G. Laparoscopic versus open resection of gastrointestinal stromal tumors of the stomach. Surg Endosc 2012. [Epub ahead of print]

70. Novitsky YW, Kercher KW, Sing RF, Heniford BT. Long-term outcomes of laparoscopic resection of gastric gastrointestinal stromal tumors. Ann Surg 2006;243:738-745.

71. Sexton JA, Pierce RA, Halpin VJ, Eagon JC, Hawkins WG, Linehan DC, et al. Laparoscopic gastric resection for gastrointestinal stromal tumors. Surg Endosc 2008;22:2583-2587.

72. Kim KH, Kim MC, Jung GJ, Kim SJ, Jang JS, Kwon HC. Long term survival results for gastric GIST: is laparoscopic surgery for large gastric GIST feasible? World J Surg Oncol 2012;10:230.

73. Lee JS, Kim JJ, Park SM. Totally laparoscopic resection for a large gastrointestinal stromal tumor of stomach. J Gastric
Cancer 2011;11:239-242.

74. Sokolich J, Galanopoulos C, Dunn E, Linder JD, Jeyarajah DR. Expanding the indications for laparoscopic gastric resection for gastrointestinal stromal tumors. JSLS 2009;13:165169.

75. Thakkar DV, Wani SV, Shetty V, Patankar RV. Laparoscopic sleeve gastrectomy for a large gastrointestinal stromal tumor. Surg Laparosc Endosc Percutan Tech 2012;22:e61-62.

76. Henckens T, Van de Putte D, Van Renterghem K, Ceelen W, Pattyn P, Van Nieuwenhove Y. Laparoendoscopic single-site gastrectomy for a gastric GIST using double-bended instruments. J Laparoendosc Adv Surg Tech A 2010;20:469-471.

77. Sasaki A, Koeda K, Nakajima J, Obuchi T, Baba S, Wakabayashi G. Single-incision laparoscopic gastric resection for submucosal tumors: report of three cases. Surg Today 2011;41:133-136.

78. Wu SD, Kong J, Su Y, Fan Y. Safety and application of transumbilical single-incision laparoscopic gastrectomy for GIST: SILS in benign gastric disease. Surg Innov 2012. [Epub ahead of print]

79. Hirano Y, Watanabe T, Uchida T, Yoshida S, Kato H, Hosokawa O. Laparoendoscopic single site partial resection of the stomach for gastrointestinal stromal tumor. Surg Laparosc Endosc Percutan Tech 2010;20:262-264.

80. Moriyama H, Ishikawa N, Kawaguchi M, Hirose K, Watanabe G. Robot-assisted laparoscopic resection for gastric gastrointestinal stromal tumor. Surg Laparosc Endosc Percutan Tech 2012;22:e155-156.

81. Buchs NC, Bucher P, Pugin F, Hagen ME, Morel P. Robotassisted oncologic resection for large gastric gastrointestinal stromal tumor: a preliminary case series. J Laparoendosc Adv Surg Tech A 2010;20:411-415.

82. Sasaki A, Koeda K, Obuchi T, Nakajima J, Nishizuka S, Terashima M, et al. Tailored laparoscopic resection for suspected gastric gastrointestinal stromal tumors. Surgery 2010;147:516-520.

83. Privette A, McCahill L, Borrazzo E, Single RM, Zubarik R. Laparoscopic approaches to resection of suspected gastric gastrointestinal stromal tumors based on tumor location. Surg Endosc 2008;22:487-494.

84. Kakeji Y, Nakanoko T, Yoshida R, Eto K, Kumashiro R, Ikeda $\mathrm{K}$, et al. Laparoscopic resection for gastrointestinal stromal tumors in the stomach. Surg Today 2012;42:554-558.

85. Hyung WJ, Lim JS, Cheong JH, Kim J, Choi SH, Noh SH. 
Laparoscopic resection of a huge intraluminal gastric submucosal tumor located in the anterior wall: eversion method. J Surg Oncol 2005;89:95-98.

86. Hepworth CC, Menzies D, Motson RW. Minimally invasive surgery for posterior gastric stromal tumors. Surg Endosc 2000;14:349-353.

87. Ibrahim IM, Silvestri F, Zingler B. Laparoscopic resection of posterior gastric leiomyoma. Surg Endosc 1997;11:277-279.

88. Hwang SH, Park do J, Kim YH, Lee KH, Lee HS, Kim HH, et al. Laparoscopic surgery for submucosal tumors located at the esophagogastric junction and the prepylorus. Surg Endosc 2009;23:1980-1987.

89. Wilhelm D, von Delius S, Burian M, Schneider A, Frimberger E, Meining A, et al. Simultaneous use of laparoscopy and endoscopy for minimally invasive resection of gastric subepithelial masses - analysis of 93 interventions. World J Surg 2008;32:1021-1028.

90. Wong DC, Wong SK, Leung AL, Chung CC, Li MK. Combined endolaparoscopic intragastric excision for gastric neoplasms. J Laparoendosc Adv Surg Tech A 2009;19:765-770.

91. Sakamoto Y, Sakaguchi Y, Akimoto H, Chinen Y, Kojo M, Sugiyama $M$, et al. Safe laparoscopic resection of a gastric gastrointestinal stromal tumor close to the esophagogastric junction. Surg Today 2012;42:708-711.

92. Song KY, Kim SN, Park CH. Tailored-approach of laparoscopic wedge resection for treatment of submucosal tumor near the esophagogastric junction. Surg Endosc 2007;21: 2272-2276.

93. Ma JJ, Hu WG, Zang L, Yan XW, Lu AG, Wang ML, et al. Laparoscopic gastric resection approaches for gastrointestinal stromal tumors of stomach. Surg Laparosc Endosc Percutan Tech 2011;21:101-105.

94. Warsi AA, Peyser PM. Laparoscopic resection of gastric GIST and benign gastric tumours: evolution of a new technique. Surg Endosc 2010;24:72-78.

95. Ludwig K, Wilhelm L, Scharlau U, Amtsberg G, Bernhardt J. Laparoscopic-endoscopic rendezvous resection of gastric tumors. Surg Endosc 2002;16:1561-1565.

96. Tagaya N, Mikami H, Kogure H, Kubota K, Hosoya Y, Nagai H. Laparoscopic intragastric stapled resection of gastric submucosal tumors located near the esophagogastric junction. Surg Endosc 2002;16:177-179.

97. Sahm M, Pross M, Lippert H. Intraluminal resection of gastric tumors using intragastric trocar technique. Surg Laparosc
Endosc Percutan Tech 2011;21:e169-172.

98. Walsh RM, Ponsky J, Brody F, Matthews BD, Heniford BT. Combined endoscopic/laparoscopic intragastric resection of gastric stromal tumors. J Gastrointest Surg 2003;7:386-392.

99. Sekimoto M, Tamura S, Hasuike Y, Yano M, Murata A, Inoue $\mathrm{M}$, et al. A new technique for laparoscopic resection of a submucosal tumor on the posterior wall of the gastric fundus. Surg Endosc 1999;13:71-74.

100. Shim JH, Lee HH, Yoo HM, Jeon HM, Park CH, Kim JG, et al. Intragastric approach for submucosal tumors located near the Z-line: a hybrid laparoscopic and endoscopic technique. J Surg Oncol 2011;104:312-315.

101. Uchikoshi F, Ito T, Nishida T, Kitagawa T, Endo S, Matsuda H. Laparoscopic intragastric resection of gastric stromal tumor located at the esophago-cardiac junction. Surg Laparosc Endosc Percutan Tech 2004;14:1-4.

102. Rosen MJ, Heniford BT. Endoluminal gastric surgery: the modern era of minimally invasive surgery. Surg Clin North Am 2005;85:989-1007, vii.

103. Li VK, Hung WK, Chung CK, Ying MW, Lam BY, Kan DM, et al. Laparoscopic intragastric approach for stromal tumours located at the posterior gastric wall. Asian J Surg 2008;31:6-10.

104. Tagaya N, Mikami H, Kubota K. Laparoscopic resection of gastrointestinal mesenchymal tumors located in the upper stomach. Surg Endosc 2004;18:1469-1474.

105. Hiki N, Yamamoto Y, Fukunaga T, Yamaguchi T, Nunobe S, Tokunaga M, et al. Laparoscopic and endoscopic cooperative surgery for gastrointestinal stromal tumor dissection. Surg Endosc 2008;22:1729-1735.

106. Abe N, Takeuchi H, Yanagida O, Masaki T, Mori T, Sugiyama $\mathrm{M}$, et al. Endoscopic full-thickness resection with laparoscopic assistance as hybrid NOTES for gastric submucosal tumor. Surg Endosc 2009;23:1908-1913.

107. Tsujimoto H, Yaguchi Y, Kumano I, Takahata R, Ono S, Hase K. Successful gastric submucosal tumor resection using laparoscopic and endoscopic cooperative surgery. World J Surg 2012;36:327-330.

108. Palmes D, Weilinghoff M, Colombo-Benkmann M, Senninger $\mathrm{N}$, Bruewer M. Effect of pyloric drainage procedures on gastric passage and bile reflux after esophagectomy with gastric conduit reconstruction. Langenbecks Arch Surg 2007;392:135141.

109. Lee JS, Kim JJ, Park SM. Laparoscopic gastric wedge resection and prophylactic antireflux surgery for a submucosal tumor of 
gastroesophageal junction. J Gastric Cancer 2011;11:131-134.

110. Huang ZG, Zhang XS, Huang SL, Yuan XG. Endoscopy dissection of small stromal tumors emerged from the muscularis propria in the upper gastrointestinal tract: Preliminary study. World J Gastrointest Endosc 2012;4:565-570.

111. Huang LY, Cui J, Liu YX, Wu CR, Yi DL. Endoscopic therapy for gastric stromal tumors originating from the muscularis propria. World J Gastroenterol 2012;18:3465-3471.

112. Jeong ID, Jung SW, Bang SJ, Shin JW, Park NH, Kim do H. Endoscopic enucleation for gastric subepithelial tumors originating in the muscularis propria layer. Surg Endosc 2011;25:468474.

113. Lee IL, Lin PY, Tung SY, Shen CH, Wei KL, Wu CS. Endoscopic submucosal dissection for the treatment of intraluminal gastric subepithelial tumors originating from the muscularis propria layer. Endoscopy 2006;38:1024-1028.

114. Białek A, Wiechowska-Kozłowska A, Pertkiewicz J, Polkowski M, Milkiewicz P, Karpińska K, et al. Endoscopic submucosal dissection for treatment of gastric subepithelial tumors (with video). Gastrointest Endosc 2012;75:276-286.

115. Li QL, Yao LQ, Zhou PH, Xu MD, Chen SY, Zhong YS, et al. Submucosal tumors of the esophagogastric junction originating from the muscularis propria layer: a large study of endoscopic submucosal dissection (with video). Gastrointest Endosc 2012;75:1153-1158.

116. Bai J, Wang Y, Guo H, Zhang P, Ling X, Zhao X. Endoscopic resection of small gastrointestinal stromal tumors. Dig Dis Sci 2010;55:1950-1954.

117. Catalano F, Rodella L, Lombardo F, Silano M, Tomezzoli A, Fuini A, et al. Endoscopic submucosal dissection in the treatment of gastric submucosal tumors: results from a retrospective cohort study. Gastric Cancer 2012. [Epub ahead of print]

118. Kakushima N, Yahagi N, Fujishiro M, Kodashima S, Nakamura M, Omata M. Efficacy and safety of endoscopic submucosal dissection for tumors of the esophagogastric junction. Endoscopy 2006;38:170-174.

119. Waterman AL, Grobmyer SR, Cance WG, Hochwald SN. Is endoscopic resection of gastric gastrointestinal stromal tumors safe? Am Surg 2008;74:1186-1189.

120. Wang L, Ren W, Fan CQ, Li YH, Zhang X, Yu J, et al. Fullthickness endoscopic resection of nonintracavitary gastric stromal tumors: a novel approach. Surg Endosc 2011;25:641647.

121. Zhou PH, Yao LQ, Qin XY, Cai MY, Xu MD, Zhong YS, et al.
Endoscopic full-thickness resection without laparoscopic assistance for gastric submucosal tumors originated from the muscularis propria. Surg Endosc 2011;25:2926-2931.

122. Gold JS, Gönen M, Gutiérrez A, Broto JM, García-del-Muro $\mathrm{X}$, Smyrk TC, et al. Development and validation of a prognostic nomogram for recurrence-free survival after complete surgical resection of localised primary gastrointestinal stromal tumour: a retrospective analysis. Lancet Oncol 2009;10:10451052.

123. Edge SB, Byrd DR, Compton CC, Fritz AG, Greene FL, Trotti A, et al. AJCC Cancer Staging Handbook; from the AJCC Cancer Staging Manual. 7th ed. New York: Springer-Verlag, 2010:170-180.

124. Dematteo RP, Ballman KV, Antonescu CR, Maki RG, Pisters PW, Demetri GD, et al; American College of Surgeons Oncology Group (ACOSOG) Intergroup Adjuvant GIST Study Team. Adjuvant imatinib mesylate after resection of localised, primary gastrointestinal stromal tumour: a randomised, double-blind, placebo-controlled trial. Lancet 2009;373:10971104.

125. Joensuu H, Eriksson M, Sundby Hall K, Hartmann JT, Pink D, Schütte J, et al. One vs three years of adjuvant imatinib for operable gastrointestinal stromal tumor: a randomized trial. JAMA 2012;307:1265-1272.

126. Joensuu H, Trent JC, Reichardt P. Practical management of tyrosine kinase inhibitor-associated side effects in GIST. Cancer Treat Rev 2011;37:75-88.

127. Reichardt P, Blay JY, Boukovinas I, Brodowicz T, Broto JM, Casali PG, et al. Adjuvant therapy in primary GIST: state-ofthe-art. Ann Oncol 2012;23:2776-2781.

128. Gouveia AM, Pimenta AP, Capelinha AF, de la Cruz D, Silva P, Lopes JM. Surgical margin status and prognosis of gastrointestinal stromal tumor. World J Surg 2008;32:2375-2382.

129. McCarter MD, Antonescu CR, Ballman KV, Maki RG, Pisters PW, Demetri GD, et al; American College of Surgeons Oncology Group (ACOSOG) Intergroup Adjuvant Gist Study Team. Microscopically positive margins for primary gastrointestinal stromal tumors: analysis of risk factors and tumor recurrence. J Am Coll Surg 2012;215:53-59.

130. Hohenberger P, Ronellenfitsch U, Oladeji O, Pink D, Ströbel $\mathrm{P}$, Wardelmann E, et al. Pattern of recurrence in patients with ruptured primary gastrointestinal stromal tumour. Br J Surg 2010;97:1854-1859.

131. Goh BK, Chow PK, Chuah KL, Yap WM, Wong WK. Patho- 
logic, radiologic and PET scan response of gastrointestinal stromal tumors after neoadjuvant treatment with imatinib mesylate. Eur J Surg Oncol 2006;32:961-963.

132. Andtbacka RH, Ng CS, Scaife CL, Cormier JN, Hunt KK, Pisters PW, et al. Surgical resection of gastrointestinal stromal tumors after treatment with imatinib. Ann Surg Oncol 2007;14:14-24.

133. Hohenberger P, Eisenberg B. Role of surgery combined with kinase inhibition in the management of gastrointestinal stromal tumor (GIST). Ann Surg Oncol 2010;17:2585-2600.

134. Doyon C, Sidéris L, Leblanc G, Leclerc YE, Boudreau D, Dubé P. Prolonged therapy with imatinib mesylate before surgery for advanced gastrointestinal stromal tumor results of a phase II trial. Int J Surg Oncol 2012;2012:761576.

135. Verweij J, Casali PG, Zalcberg J, LeCesne A, Reichardt P, Blay JY, et al. Progression-free survival in gastrointestinal stromal tumours with high-dose imatinib: randomised trial. Lancet 2004;364:1127-1134.

136. Haller F, Detken S, Schulten HJ, Happel N, Gunawan B, Kuhlgatz J, et al. Surgical management after neoadjuvant imatinib therapy in gastrointestinal stromal tumours (GISTs) with respect to imatinib resistance caused by secondary KIT mutations. Ann Surg Oncol 2007;14:526-532.

137. Blesius A, Cassier PA, Bertucci F, Fayette J, Ray-Coquard I, Bui B, et al. Neoadjuvant imatinib in patients with locally ad- vanced non metastatic GIST in the prospective BFR14 trial. BMC Cancer 2011;11:72.

138. Wang D, Zhang Q, Blanke CD, Demetri GD, Heinrich MC, Watson JC, et al. Phase II trial of neoadjuvant/adjuvant imatinib mesylate for advanced primary and metastatic/recurrent operable gastrointestinal stromal tumors: long-term follow-up results of Radiation Therapy Oncology Group 0132. Ann Surg Oncol 2012;19:1074-1080.

139. Choi H. Response evaluation of gastrointestinal stromal tumors. Oncologist 2008;13 Suppl 2:4-7.

140. Van den Abbeele AD. The lessons of GIST--PET and PET/CT: a new paradigm for imaging. Oncologist 2008;13 Suppl 2:8-13.

141. UMIN-CTR, id number UMIN000003114. Available from: https://upload.umin.ac.jp/cgi-open-bin/ctr/ctr.cgi?function=b rows\&action $=$ brows\&type $=$ summary\&recptno $=$ R000003763 \&language $=\mathrm{E}$.

142. Clinicaltrials.gov id NCT00112632. Available from: http:// www.clinicaltrials.gov/ct2/show/NCT00112632?term=neoadj uvant+gist\&rank=3.

143. Eisenberg BL, Harris J, Blanke CD, Demetri GD, Heinrich MC, Watson JC, et al. Phase II trial of neoadjuvant/adjuvant imatinib mesylate (IM) for advanced primary and metastatic/ recurrent operable gastrointestinal stromal tumor (GIST): early results of RTOG 0132/ACRIN 6665. J Surg Oncol 2009;99: 42-47. 